\title{
Canine edge width and height affect dental esthetics in maxillary canine substitution treatment
}

\author{
Ruomei Li ${ }^{1,4}$, Li Mei ${ }^{2}$, Pengfei Wang ${ }^{1}$, Jiarong He ${ }^{1}$, Qingyan Meng ${ }^{1}$, Linna Zhong ${ }^{1}$, Wei Zheng ${ }^{3^{*}}$ and Yu Li
}

\begin{abstract}
Background: To investigate the effect of canine edge width and height on dental esthetics in maxillary canine substitution treatment.

Methods: A total of 127 canine substitution treatment cases were screened and evaluated by a panel of orthodontic experts and laypersons in the pilot study. The top five subjects with the esthetically most pleasant canine substitution were included in the study, resulting in 140 computerized images displaying only the upper dentition, with different canine edge widths $(0 \%, 12.5 \%, 25 \%, 37.5 \%, 50 \%, 62.5 \%$, and $75 \%$ of the central clinical width) and heights (- $0.5 \mathrm{~mm}$, $0 \mathrm{~mm}, 0.5 \mathrm{~mm}$, and $1.0 \mathrm{~mm}$ vertically relative to the central incisor edge) finally used for the esthetic evaluation by 101 observers (41 orthodontists and 60 laypersons). The ordered logistic regression analysis, the univariate analysis of variance, the chi-square, and Fisher's exact tests were used for statistical analyses.

Results: The most esthetic canine shape for canine substitution was found to be a shape with the edge width of $62.5 \%$ of the central incisor width and the edge height of $0.5 \mathrm{~mm}$ gingival to the central incisor edge $(P<0.05)$. The canine edge width of $50-75 \%$ and height of $0.5-0 \mathrm{~mm}$ gingival to the central incisor edge were generally considered to be esthetic by all observers. Orthodontists and laypersons had the same ranking on the top two most esthetic canine shapes (edge width and height $62.5 \%$ and $0.5 \mathrm{~mm}$ gingival; $50 \%$ and $0 \mathrm{~mm}$ incisal) as well as the bottom two most unesthetic canine shape ( $0 \%$ and $0.5 \mathrm{~mm}$ gingival; $75 \%$ and $1 \mathrm{~mm}$ incisal). Male and female observers generally had similar esthetic grades and rankings on the canine shapes $(P>0.05)$.

Conclusions: The most esthetic canine shape for canine substitution is a shape with the canine edge width of $62.5 \%$ of the central incisor width and the edge height of $0.5 \mathrm{~mm}$ gingival to the central incisor edge. The different collocations of the canine edge width and height affect dental esthetics of the canine during canine substitution treatment.
\end{abstract}

\section{Background}

The maxillary front teeth play an essential role in dentofacial esthetics [1]. For example, the absence of one or both maxillary lateral incisors (either congenitally or as a result of being extracted for reasons such as diminutive tooth) can significantly impact the dentofacial appearance, oral function, psychological well-being, and quality of life of the patient [2-5]. The treatments for these missing maxillary lateral incisors usually include

\footnotetext{
* Correspondence: Zhengwei81101@163.com

${ }^{3}$ State Key Laboratory of Oral Diseases, National Clinical Research Center for Oral Diseases, Department of Oral and Maxillofacial Surgery, West China Hospital of Stomatology, Sichuan University, No.14, South Renmin Road section 3, Chengdu 610041, China

Full list of author information is available at the end of the article
}

prosthetic replacements (e.g., implantation, fixed, or removable dentures) or orthodontic space closure with canine substitution [6-10].

Numerous studies have demonstrated the advantages of canine substitution to replace the missing maxillary lateral incisor, including good esthetics [11, 12], long-term periodontal and temporomandibular joint health [13-15], and the avoidance of prosthetic materials in the oral cavity after treatment $[16,17]$, as well as reduced costs in treatment [16].

A challenge of canine substitution in practice is to recontour the shape of the canine after space closure by grinding and reshaping the canine enamel to produce esthetically pleasant edge width and height $[10,18,19]$. Clinicians usually use the maxillary central incisors as 




Fig. 1 The esthetically most pleasant (ranked as top 1) canine shape with the highest grades for the incisal width and height by all observers in the study. The canine edge width was based on the percentage of the width of the maxillary central incisor clinical crown; the canine edge height was defined as the vertical distance of the incisal edges between the maxillary canine and central incisor found to be not as perceptive and critical as the orthodontists when evaluating smile esthetics [11]. A result that was considered by orthodontists to be less than ideal may well be perfectly acceptable to the layperson $[11,22,24]$. It is important to understand the influence of the canine shape on dental esthetics during the patient-centered treatment of canine substitution $[25,26]$.

The aim of the study was to investigate the influence of the canine edge width and height on dental esthetics in canine substitution treatment.

the reference for recontouring after the lateralization of the canines $[10,18]$. However, it is still unclear what canine edge width and height is the most esthetic shape to the patients as well as to the orthodontists. A number of previous studies have found that the shade, gingival height, symmetry, crown width, crown height, and tip morphology of the substituted canine could affect the esthetic treatment outcome [19-23]. And there was a discrepancy in the esthetic perception between laypersons and orthodontists [24]. The laypersons were

\section{Material and methods Image preparation}

The study was approved by the Ethics Committee of the State Key Laboratory of Oral Disease, West China School of Stomatology, Sichuan University, China. A total of 127 orthodontic patients from the Department of Orthodontics, West China Hospital of Stomatology, Sichuan University, were screened for eligibility. The inclusion criteria are as follows: (1) subjects must have full permanent dentition with two congenitally missing

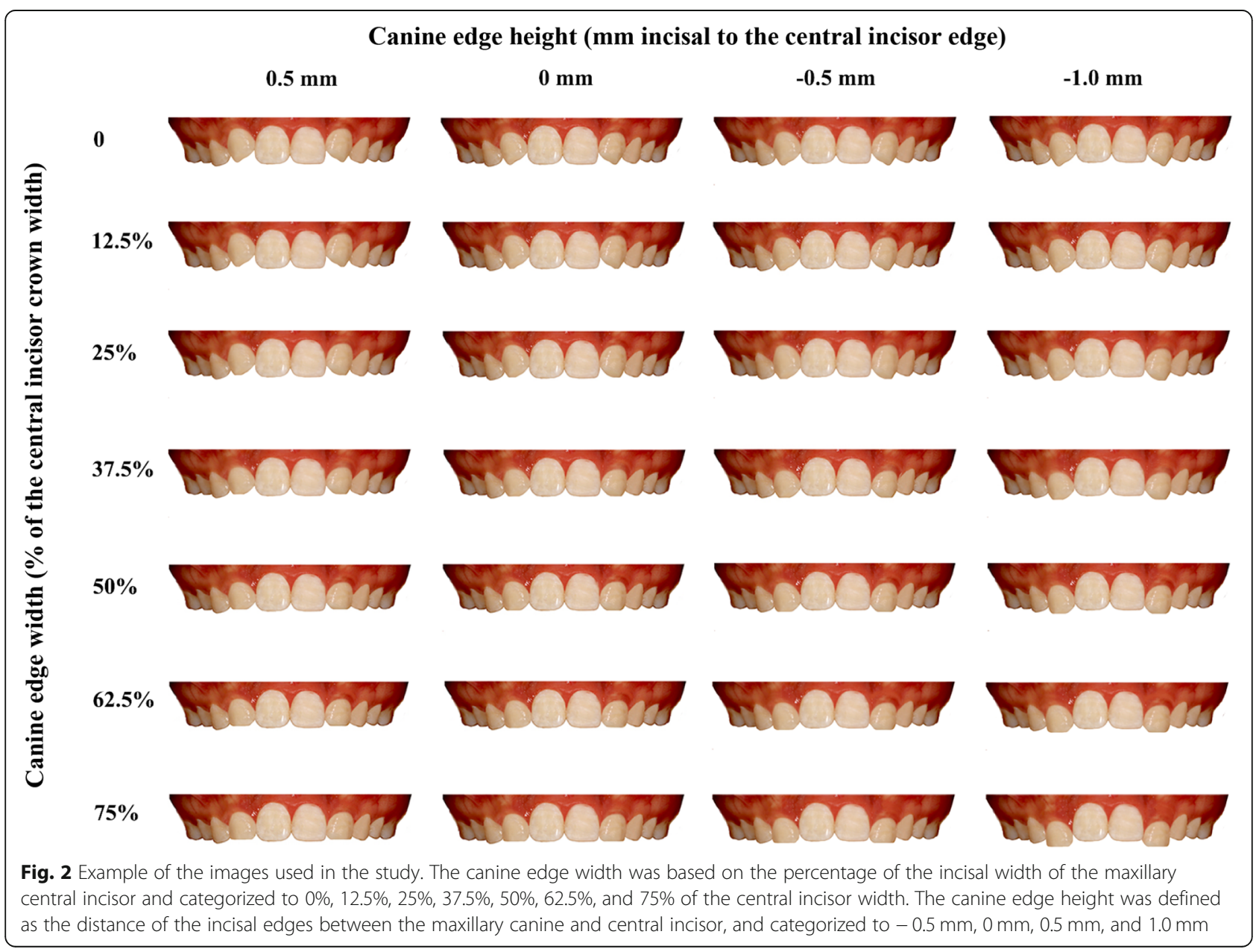


maxillary lateral incisors, (2) fixed orthodontic treatment involving canine substitution and shape modification to replace the missing lateral incisors, and (3) intraoral photographs were taken after the treatment and were of good quality. The exclusion criteria are as follows: (1) craniofacial defects or syndromes and (2) a history of restorative treatment on the anterior teeth.

The posttreatment intraoral frontal photo of each subject was cut to display only the upper dentition using Adobe Photoshop CS6 (Adobe Systems Inc. San Jose, CA, USA) (Fig. 1). These images were then evaluated by a panel of orthodontic experts and laypersons in the pilot study, and the top five subjects with the esthetically most pleasant canine substitution were included in the study. The images of those patients were subsequently processed using a computer to generate a series of images with different incisal edge width and height of the canine (Fig. 2).

The canine edge width was based on the percentage of the width of the maxillary central incisor clinical crown and categorized to $0 \%, 12.5 \%, 25 \%, 37.5 \%, 50 \%, 62.5 \%$, and $75 \%$ of the central incisor width. The canine edge height was defined as the vertical distance of the incisal edges between the maxillary canine and central incisor, and categorized to $-0.5 \mathrm{~mm}(0.5 \mathrm{~mm}$ gingival to the central incisor edge), $0 \mathrm{~mm}$ (the same height with the central incisor edge), $0.5 \mathrm{~mm}(0.5 \mathrm{~mm}$ incisal to the central incisor edge), and $1.0 \mathrm{~mm}(1.0 \mathrm{~mm}$ incisal to the central incisor edge) (Figs. 1 and 2).

A total of 140 images (28 for each subject) were finally prepared and included for the esthetic evaluation and analyses.

\section{Participants and evaluation procedures}

A total of 101 participants, including 41 orthodontists (20 male and 21 female, age range $25-30$ years) and 60 laypersons (30 male and 30 female, age range $20-30$ years) with similar socioeconomic status, were recruited to assess and grade these images based on the dental esthetics.

Each observer was asked to view and score the images using PowerPoint slides (with one image on each slide) in the same face-to-face setting. A blank slide was displayed between each image to minimize the disturbance from the former to the latter. These observers firstly viewed 10 random slides ( $3 \mathrm{~s}$ for each) to become familiar with the images before formally viewing and grading (5, very attractive; 4 , attractive; 3 , fair; 2 , poor; 1 , very poor) all the images ( $5 \mathrm{~s}$ for each) as previously described in the literature [27]. The formal assessment was subsequently repeated to allow the observers to check and modify their grades. The entire evaluation process was repeated again in the same setting 2 weeks later. The consistency of the grades was excellent for the orthodontists (Cronbach's $\alpha=0.95$ ) and was good for the laypersons (Cronbach's $\alpha=0.85$ ).

\section{Statistical analysis}

Stata 14.0 (Stata Corp, Texas, TX, USA) and SPSS 21.0 (Statistical Package for the Social Sciences, SPSS Inc., Chicago, IL, USA) were used for the statistical analysis of the data. Ordered logistic regression analysis and the univariate analysis of variance were performed to analyze the effect of canine edge width and height on dental esthetics. Subgroup analyses were performed based on the observer's background (orthodontist v.s. layperson) and

Table 1 Esthetic grade (mean \pm standard deviation) and rank on the independent canine shape parameters (edge width and height) by orthodontists and laypersons

\begin{tabular}{|c|c|c|c|c|c|c|c|c|c|c|}
\hline \multirow{2}{*}{$\begin{array}{l}\text { Canine shape } \\
\text { parameters }\end{array}$} & \multicolumn{2}{|c|}{ All observers } & \multicolumn{2}{|c|}{ Orthodontist } & \multicolumn{2}{|l|}{ Layperson } & \multicolumn{2}{|l|}{ Male } & \multicolumn{2}{|l|}{ Female } \\
\hline & Grade & $\overline{\text { Rank }}$ & Grade & $\overline{\text { Rank }}$ & Grade* & $\overline{\text { Rank }}$ & Grade* & $\overline{\text { Rank }}$ & Grade* & $\overline{\text { Rank }}$ \\
\hline \multicolumn{11}{|l|}{ Edge width } \\
\hline $0 \%$ & $2.92 \pm 1.09$ & 6 & $2.98 \pm 0.91$ & 6 & $2.84 \pm 1.21$ & 5 & $2.86 \pm 1.17$ & 6 & $2.93 \pm 1.03$ & 6 \\
\hline $12.5 \%$ & $3.06 \pm 0.99$ & 5 & $3.20 \pm 1.78$ & 5 & $2.79 \pm 1.10$ & 6 & $2.87 \pm 1.00$ & 5 & $3.04 \pm 0.96$ & 5 \\
\hline $25 \%$ & $3.14 \pm 1.04$ & 4 & $3.27 \pm 0.83$ & 4 & $2.91 \pm 1.16$ & 4 & $2.94 \pm 1.10$ & 4 & $3.18 \pm 0.97$ & 4 \\
\hline $37.5 \%$ & $3.21 \pm 1.11$ & 3 & $3.36 \pm 1.04$ & 3 & $2.98 \pm 1.13$ & 3 & $3.05 \pm 1.08$ & 3 & $3.23 \pm 1.12$ & 3 \\
\hline $50 \%$ & $3.43 \pm 1.18$ & 1 & $3.53 \pm 1.39$ & 1 & $3.36 \pm 0.98$ & 1 & $3.40 \pm 1.05$ & 1 & $3.46 \pm 1.27$ & 1 \\
\hline $62.5 \%$ & $3.30 \pm 1.29$ & 2 & $3.37 \pm 1.37$ & 2 & $3.26 \pm 1.23$ & 2 & $3.22 \pm 1.18$ & 2 & $3.38 \pm 1.36$ & 2 \\
\hline $75 \%$ & $2.74 \pm 1.34$ & 7 & $2.77 \pm 1.48$ & 7 & $2.72 \pm 1.23$ & 7 & $2.72 \pm 1.23$ & 7 & $2.76 \pm 1.41$ & 7 \\
\hline \multicolumn{11}{|l|}{ Edge height } \\
\hline$-0.5 \mathrm{~mm}$ & $3.15 \pm 1.25$ & 2 & $3.40 \pm 1.24$ & 2 & $3.02 \pm 1.22$ & 2 & $3.08 \pm 1.23$ & 2 & $3.25 \pm 1.25$ & 2 \\
\hline $0 \mathrm{~mm}$ & $3.46 \pm 1.03$ & 1 & $3.86 \pm 0.88$ & 1 & $3.19 \pm 1.06$ & 1 & $3.31 \pm 1.04$ & 1 & $3.61 \pm 1.00$ & 1 \\
\hline $0.5 \mathrm{~mm}$ & $3.13 \pm 1.03$ & 3 & $3.30 \pm 0.87$ & 3 & $2.99 \pm 1.13$ & 3 & $3.05 \pm 1.08$ & 3 & $3.18 \pm 0.99$ & 3 \\
\hline $1.0 \mathrm{~mm}$ & $2.55 \pm 1.16$ & 4 & $2.29 \pm 0.99$ & 4 & $2.73 \pm 1.22$ & 4 & $2.58 \pm 1.10$ & 4 & $2.52 \pm 1.19$ & 4 \\
\hline
\end{tabular}

*Data represent mean \pm standard deviation 
gender (male v.s. female) by using the chi-square and Fisher's exact tests. $P$ values of less than 0.05 were considered statistically significant.

\section{Results}

\section{Canine edge width and height}

The canine edge widths of $50 \%$ and $62.5 \%$ of the central incisor width were ranked as top 1 and 2, respectively, by all observers (Table 1 and Fig. 2). The canine edge heights of $0 \mathrm{~mm}$ and $-0.5 \mathrm{~mm}$ incisal to the central incisor edge were ranked as top 1 and 2, respectively, by all observers (Table 1 and Fig. 2).

The ordered logistic regression analysis revealed that both the canine edge width (odds ratio $=1.21,95 \%$ confidence interval $(95 \% \mathrm{CI})=1.19-1.23, P=0.003)$ and canine edge height (odds ratio $=1.93,95 \% \mathrm{CI}=1.84-2.02$, $P=0.001)$ had statistically significant influence on the dental esthetics. The univariate analysis of variance showed that the different collocations of these two canine shape parameters (i.e., edge width and height) also influenced the dental esthetics (Table 2).

Figure 1 was considered as the esthetically most pleasant (ranked as top 1) canine shape by all observers (Table 2 and Fig. 1). The top 2 esthetically most pleasant canine shape collocation was $50 \%$ width and $0 \mathrm{~mm}$ height; the bottom 1 and bottom 2 esthetically most unpleasant canine shape collocations were $0 \%$ width and $-0.5 \mathrm{~mm}$ height, and $75 \%$ width and $1.0 \mathrm{~mm}$ height, respectively (Table 2). The effect of canine edge height $(F=486.40$, $P<0.001)$ on dental esthetics depended on the canine edge width $(F=13.89, P<0.001)$, and vice versa $(F=53.45$, $P<0.001$ ).

Subgroup analyses on observers' background and gender The subgroup analyses on the observers' background (orthodontist v.s. layperson) and gender (male v.s. female) were performed using the chi-square and Fisher's exact tests and were summarized in Tables 3 and 4 and Fig. 3.

The orthodontists and laypersons had different esthetic grades and rankings on the canine shapes in general (Table 3 and Fig. 3), with the greatest discrepancy found in the canine shape of $37.5 \%$ width and $0.5 \mathrm{~mm}$ height (i.e., this canine shape was ranked as the top 7th by the orthodontists but ranked as the 19th by the laypersons). But both orthodontists and laypersons had the same ranking on the top two most esthetic canine shapes $(62.5 \%$ edge width and $-0.5 \mathrm{~mm}$ height, and $50 \%$ width and $0 \mathrm{~mm}$ height) as well as the bottom two most unaesthetic canine shape $(0 \%$ width and $-0.5 \mathrm{~mm}$ height, and $75 \%$ width and $1 \mathrm{~mm}$ height).

Male and female observers generally had similar esthetic grades and rankings on the canine shapes $(P>0.05)$. The canine shapes (edge width and height) of $62.5 \%$ and -0.5 $\mathrm{mm}$ as well as $50 \%$ and $0 \mathrm{~mm}$ were also ranked as top 1
Table 2 Esthetic grade (mean \pm standard deviation) and rank on the canine shape by all observers

\begin{tabular}{|c|c|c|c|}
\hline \multicolumn{2}{|l|}{ Canine shape } & \multicolumn{2}{|l|}{ All observers } \\
\hline Edge width (\%) & Edge height (mm) & Grade & Rank \\
\hline 62.5 & -0.5 & $4.38 \pm 0.60$ & 1 \\
\hline 50 & 0 & $4.17 \pm 0.76$ & 2 \\
\hline 50 & -0.5 & $4.08 \pm 0.75$ & 3 \\
\hline 62.5 & 0 & $3.89 \pm 0.48$ & 4 \\
\hline 75 & -0.5 & $3.88 \pm 0.64$ & 5 \\
\hline 37.5 & 0 & $3.76 \pm 0.69$ & 6 \\
\hline 25 & 0 & $3.64 \pm 0.27$ & 7 \\
\hline 0 & 0.5 & $3.47 \pm 0.24$ & 8 \\
\hline 75 & 0 & $3.45 \pm 0.46$ & 9 \\
\hline 37.5 & 0.5 & $3.40 \pm 0.70$ & 10 \\
\hline 12.5 & 0.5 & $3.38 \pm 0.23$ & 11 \\
\hline 25 & 0.5 & $3.27 \pm 0.52$ & 12 \\
\hline 12.5 & 1.0 & $3.23 \pm 0.22$ & 13 \\
\hline 0 & 1.0 & $3.22 \pm 0.19$ & 14 \\
\hline 50 & 0.5 & $3.22 \pm 0.26$ & 15 \\
\hline 37.5 & -0.5 & $3.02 \pm 0.11$ & 16 \\
\hline 62.5 & 0.5 & $2.92 \pm 0.33$ & 17 \\
\hline 12.50 & 0 & $2.92 \pm 0.19$ & 18 \\
\hline 0 & 0 & $2.92 \pm 0.30$ & 19 \\
\hline 25 & 1.0 & $2.72 \pm 0.25$ & 20 \\
\hline 25 & -0.5 & $2.66 \pm 0.30$ & 21 \\
\hline 37.5 & 1.0 & $2.44 \pm 0.34$ & 22 \\
\hline 12.50 & -0.5 & $2.43 \pm 0.11$ & 23 \\
\hline 50 & 1.0 & $2.33 \pm 0.90$ & 24 \\
\hline 75 & 0.5 & $2.23 \pm 0.28$ & 25 \\
\hline 62.5 & 1.0 & $2.06 \pm 0.55$ & 26 \\
\hline 0 & -0.5 & $1.90 \pm 0.09$ & 27 \\
\hline 75 & 1.0 & $1.43 \pm 0.60$ & 28 \\
\hline
\end{tabular}

and top 2 by both the male and female observers, but their bottom ranking of the most unaesthetic canine shape was the collocations of $75 \%$ and $1 \mathrm{~mm}$ (Table 4 and Fig. 3).

\section{Discussion}

An esthetic reshapement of the canine plays an important role in a successful canine substitution treatment. This study investigated the influence of the canine edge width and height on dental esthetics and found that the esthetically most pleasant canine edge widths were $50 \%$ and $62.5 \%$ of the central incisor width and the esthetically most pleasant canine edge heights were $0 \mathrm{~mm}$ and $-0.5 \mathrm{~mm}$ incisal to the central incisor edge. There was an interaction between the width and height of the canine edge on the dental esthetics, with the $62.5 \%$ width and $-0.5 \mathrm{~mm}$ height considered to be the esthetically 
Table 3 Esthetic grade (mean \pm standard deviation) and rank on the canine shape by the orthodontists and laypersons. The $P$ values were based on the chi-square and Fisher's exact tests between the orthodontists' and laypersons' grades

\begin{tabular}{|c|c|c|c|c|c|c|}
\hline \multicolumn{2}{|l|}{ Canine shape } & \multicolumn{2}{|c|}{ Orthodontist } & \multicolumn{2}{|l|}{ Layperson } & \multirow[b]{2}{*}{$P$ values } \\
\hline Edge width (\%) & Edge height (mm) & Grade & $\overline{\text { Rank }}$ & Grade & $\overline{\text { Rank }}$ & \\
\hline 0 & -0.5 & $1.67 \pm 0.64$ & 27 & $2.13 \pm 1.22$ & 27 & 0.04 \\
\hline 0 & 0 & $2.93 \pm 0.65$ & 18 & $2.63 \pm 0.87$ & 22 & 0.59 \\
\hline 0 & 0.5 & $3.63 \pm 0.71$ & 11 & $3.30 \pm 1.16$ & 9 & 0.02 \\
\hline 0 & 1.0 & $3.07 \pm 0.68$ & 15 & $3.35 \pm 1.05$ & 8 & 0.55 \\
\hline 12.5 & -0.5 & $2.50 \pm 0.60$ & 22 & $2.35 \pm 0.80$ & 26 & 0.65 \\
\hline 12.5 & 0 & $3.13 \pm 0.58$ & 14 & $2.70 \pm 0.99$ & 20 & 0.64 \\
\hline 12.5 & 0.5 & $3.53 \pm 0.53$ & 12 & $3.23 \pm 1.07$ & 11 & 0.42 \\
\hline 12.5 & 1.0 & $3.40 \pm 0.80$ & 13 & $3.08 \pm 1.27$ & 15 & 0.79 \\
\hline 25 & -0.5 & $2.87 \pm 0.53$ & 19 & $2.45 \pm 1.08$ & 25 & 0.06 \\
\hline 25 & 0 & $3.83 \pm 0.60$ & 8 & $3.45 \pm 1.13$ & 5 & $<0.01$ \\
\hline 25 & 0.5 & $3.63 \pm 0.71$ & 10 & $2.90 \pm 1.17$ & 17 & $<0.01$ \\
\hline 25 & 1.0 & $2.53 \pm 0.59$ & 21 & $2.90 \pm 1.15$ & 18 & $<0.01$ \\
\hline 37.5 & -0.5 & $2.97 \pm 0.76$ & 17 & $3.10 \pm 1.15$ & 14 & 0.67 \\
\hline 37.5 & 0 & $4.23 \pm 0.64$ & 5 & $3.28 \pm 1.13$ & 10 & $<0.01$ \\
\hline 37.5 & 0.5 & $3.87 \pm 0.52$ & 7 & $2.90 \pm 1.08$ & 19 & $<0.01$ \\
\hline 37.5 & 1.0 & $2.20 \pm 0.49$ & 23 & $2.68 \pm 1.07$ & 21 & 0.19 \\
\hline 50 & -0.5 & $4.60 \pm 0.55$ & 3 & $3.55 \pm 0.99$ & 4 & $<0.01$ \\
\hline 50 & 0 & $4.70 \pm 0.49$ & 2 & $3.63 \pm 0.87$ & 2 & $<0.01$ \\
\hline 50 & 0.5 & $3.03 \pm 0.60$ & 16 & $3.40 \pm 0.90$ & 7 & 0.94 \\
\hline 50 & 1.0 & $2.00 \pm 0.67$ & 25 & $2.95 \pm 1.06$ & 16 & $<0.01$ \\
\hline 62.5 & -0.5 & $4.80 \pm 0.39$ & 1 & $3.95 \pm 0.75$ & 1 & $<0.01$ \\
\hline 62.5 & 0 & $4.23 \pm 0.58$ & 6 & $3.57 \pm 1.13$ & 3 & $<0.01$ \\
\hline 62.5 & 0.5 & $2.70 \pm 0.73$ & 20 & $3.15 \pm 1.17$ & 12 & 0.25 \\
\hline 62.5 & 1.0 & $1.77 \pm 0.42$ & 26 & $2.45 \pm 1.22$ & 24 & 0.02 \\
\hline 75 & -0.5 & $4.37 \pm 0.89$ & 4 & $3.43 \pm 1.13$ & 6 & 0.16 \\
\hline 75 & 0 & $3.77 \pm 0.82$ & 9 & $3.13 \pm 0.85$ & 13 & $<0.01$ \\
\hline 75 & 0.5 & $2.13 \pm 0.48$ & 24 & $2.53 \pm 1.15$ & 23 & $<0.01$ \\
\hline 75 & 1.0 & $1.00 \pm 0.01$ & 28 & $1.85 \pm 1.12$ & 28 & 0.32 \\
\hline
\end{tabular}

most pleasant canine shape for the canine substitution treatment by all observers in the study.

The shape of maxillary central incisor is generally used as the reference for reshaping the canines during canine substitution treatment $[10,18]$. The most esthetic width ratio of the maxillary lateral and central incisors has been considered to vary from $0.62: 1$ to $0.72: 1$ [28-31]. The canine edge width of $62.5 \%$ of the central incisor width in the study, which was ranked as top 1, was also the closest ratio to the naturally esthetic standard ratio [11, 24].

The canine shapes with relatively pronounced cusps (i.e., $0 \%-12.5 \%$ width and $0.5 \mathrm{~mm}$ height; $25 \%-37.5 \%$ width and $0 \mathrm{~mm}$ height) were preferred by a considerable number of observers, who regarded them as a symbol of youth and vitality in the study. This is different from the findings of other studies, in which they demonstrated that the esthetic-reshaped canine shares a similar contour with a natural lateral incisor [24, 32] and the deviation may be due to the morphological distinction between the canine and lateral incisor.

The canine edge height has been found to play an important role in the smile arc [33] and gingival margin $[34,35]$. The gingival height of canine in our study was relatively more incisal compared with a previous study [34]. It should be noted that the height of gingival margin was digitally altered in the same amount as canine did in the study, but the actual gingival change is usually less than the tooth height change in the real tooth movement due to a delayed or limited periodontal remodeling. Considering that the soft tissues such as gingiva and lips may potentially affect the observers' grades and rankings on the dental esthetics, the images 
Table 4 Esthetic grade (mean \pm standard deviation) and rank on the canine shape by the male and female observers. The $P$ values were based on the chi-square and Fisher's exact tests between male and female observers' grades

\begin{tabular}{|c|c|c|c|c|c|c|}
\hline \multicolumn{2}{|l|}{ Canine shape } & \multicolumn{2}{|l|}{ Male } & \multicolumn{2}{|l|}{ Female } & \multirow[b]{2}{*}{$P$ value } \\
\hline Edge width (\%) & Edge height $(\mathrm{mm})$ & Grade & Rank & Grade & Rank & \\
\hline 0 & -0.5 & $1.90 \pm 0.94$ & 27 & $2.27 \pm 1.12$ & 26 & 0.32 \\
\hline 0 & 0 & $2.70 \pm 0.86$ & 19 & $2.88 \pm 0.74$ & 19 & 0.11 \\
\hline 0 & 0.5 & $3.60 \pm 1.18$ & 6 & $3.33 \pm 0.90$ & 12 & 0.25 \\
\hline 0 & 1.0 & $3.24 \pm 0.96$ & 10 & $3.22 \pm 0.96$ & 15 & 0.22 \\
\hline 12.5 & -0.5 & $2.30 \pm 0.68$ & 26 & $2.51 \pm 0.77$ & 22 & 0.12 \\
\hline 12.5 & 0 & $2.78 \pm 0.81$ & 18 & $2.94 \pm 0.92$ & 18 & 0.48 \\
\hline 12.5 & 0.5 & $3.22 \pm 1.02$ & 11 & $3.49 \pm 0.74$ & 8 & 0.84 \\
\hline 12.5 & 1.0 & $3.20 \pm 1.15$ & 12 & $3.24 \pm 1.12$ & 14 & 0.16 \\
\hline 25 & -0.5 & $2.38 \pm 0.91$ & 23 & $2.80 \pm 0.85$ & 21 & 0.05 \\
\hline 25 & 0 & $3.60 \pm 1.02$ & 7 & $3.65 \pm 0.93$ & 6 & 0.02 \\
\hline 25 & 0.5 & $3.14 \pm 1.11$ & 15 & $3.37 \pm 0.85$ & 11 & 0.54 \\
\hline 25 & 1.0 & $2.62 \pm 0.98$ & 21 & $2.84 \pm 0.97$ & 20 & 0.99 \\
\hline 37.5 & -0.5 & $3.06 \pm 1.08$ & 16 & $3.04 \pm 0.99$ & 16 & 0.29 \\
\hline 37.5 & 0 & $3.68 \pm 1.09$ & 5 & $3.48 \pm 0.81$ & 9 & $<0.01$ \\
\hline 37.5 & 0.5 & $3.16 \pm 1.11$ & 13 & $3.63 \pm 0.99$ & 7 & 0.31 \\
\hline 37.5 & 1.0 & $2.56 \pm 0.92$ & 22 & $2.43 \pm 0.90$ & 23 & 0.99 \\
\hline 50 & -0.5 & $3.90 \pm 0.92$ & 3 & $3.98 \pm 1.02$ & 4 & 0.99 \\
\hline 50 & 0 & $3.92 \pm 0.93$ & 2 & $4.24 \pm 0.78$ & 2 & 0.17 \\
\hline 50 & 0.5 & $3.16 \pm 0.76$ & 14 & $3.31 \pm 0.82$ & 13 & 0.99 \\
\hline 50 & 1.0 & $2.62 \pm 1.04$ & 20 & $2.31 \pm 1.12$ & 25 & 0.99 \\
\hline 62.5 & -0.5 & $4.10 \pm 0.77$ & 1 & $4.41 \pm 0.67$ & 1 & 0.42 \\
\hline 62.5 & 0 & $3.54 \pm 1.12$ & 8 & $4.08 \pm 0.85$ & 3 & 0.03 \\
\hline 62.5 & 0.5 & $2.94 \pm 1.09$ & 17 & $2.98 \pm 1.03$ & 17 & 0.99 \\
\hline 62.5 & 1.0 & $2.30 \pm 0.94$ & 25 & $2.04 \pm 1.06$ & 27 & 0.99 \\
\hline 75 & -0.5 & $3.74 \pm 1.12$ & 4 & $3.73 \pm 1.18$ & 5 & 0.30 \\
\hline 75 & 0 & $3.26 \pm 0.88$ & 9 & $3.45 \pm 0.91$ & 10 & 0.16 \\
\hline 75 & 0.5 & $2.36 \pm 0.91$ & 24 & $2.35 \pm 0.97$ & 24 & 0.99 \\
\hline 75 & 1.0 & $1.52 \pm 0.80$ & 28 & $1.53 \pm 1.01$ & 28 & 0.62 \\
\hline
\end{tabular}

used in the current study only included the upper dentition [19].

One of the limitations of the study is that the evaluation of dental esthetics was focused on the canine edge (width and height) and was performed on two-dimensional images displaying the upper dentition only. The other canine shape parameters, such as clinical crown width and height, were not assessed in the study. Though we found that the dental esthetics of canine following the canine substitution treatment were influenced by not only the independent parameters of the canine (i.e., edge width and height) but also the different collocations of these two parameters, the other factors, including crown torque [36, 37], enamel color [20, 38, 39], gingival margin [34, 35], and lip position [5], can also affect dental esthetics during the canine substitution treatment. Furthermore, it is important to note that the natural tooth morphology of the anterior teeth can also vary among different ages and genders [40].

Oberservers of different genders and professions may have different expectations in canine substitution treatment cases. In the study, canine shapes of $50-75 \%$ edge width and $-0.5-0 \mathrm{~mm}$ edge height are widely preferred by all observers. The orthodontists had a greater consistency in grading and ranking the images used in the study than did the laypersons, which was in agreement with the previous studies [20,41]. This may be because the orthodontists were trained and able to perceive a minor difference in teeth morphology $[14,41]$. Additionally, in terms of the pronounced canine cusp (e.g., $0-25 \%$ width and $0.5 \mathrm{~mm}$ 


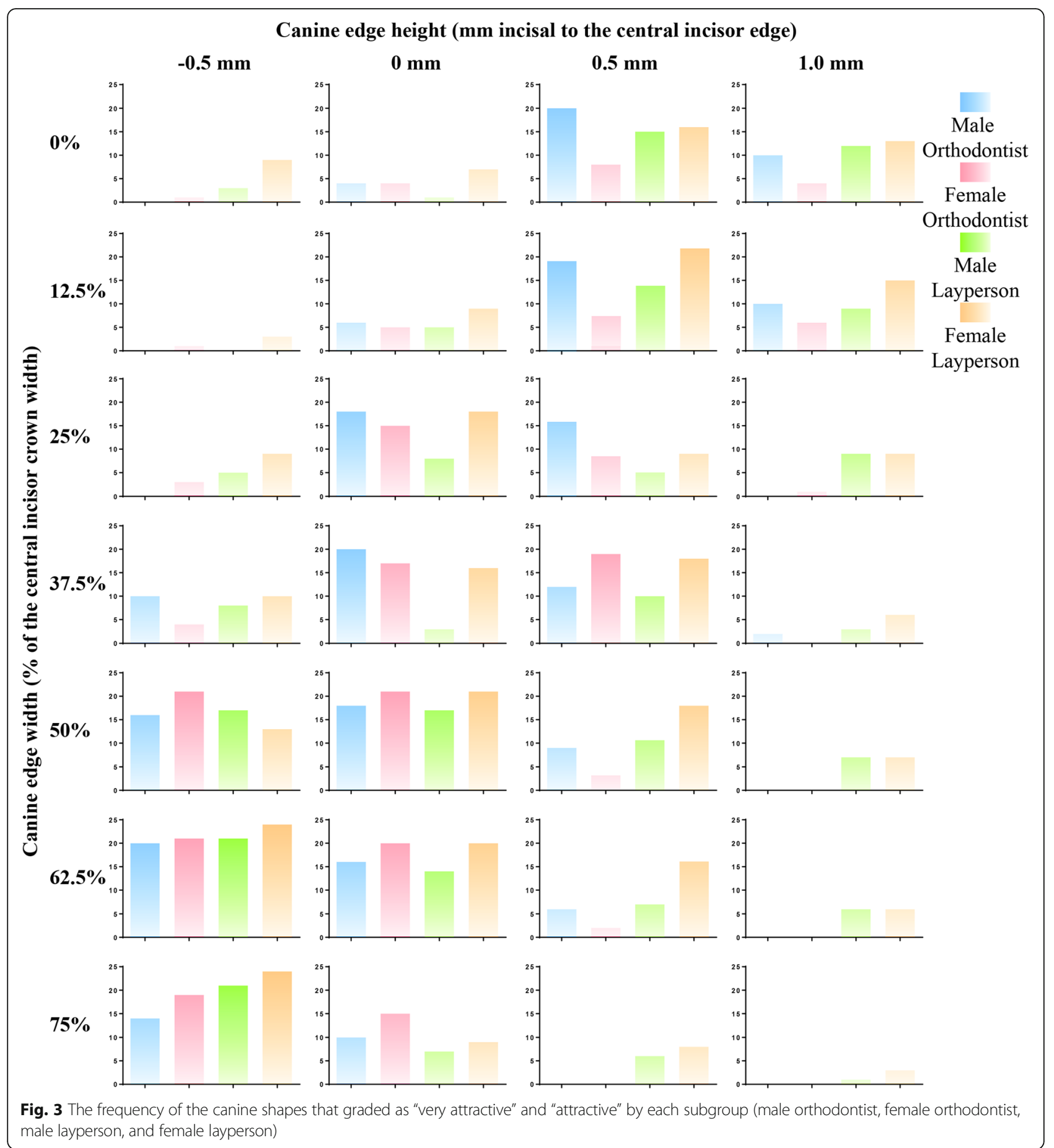

height), the number of male orthodontists showed more preference than did the female orthodontists. In comparison with the orthodontist, the layperson seemed to have less tolerance on the canine shapes with the edge width of 25 to $37.5 \%$ and the edge height of $0 \mathrm{~mm}$.

It is also important to note that there were a number of patients and orthodontists who considered a relatively pronounced canine cusp (e.g., 0 to $12.5 \%$ width and 0 to
$0.5 \mathrm{~mm}$ height) to be esthetically attractive. Considering that the canine shape with a relatively pronounced cusp involves relatively less enamel grinding, a customized patient-centered preference of the canine shape (instead of the natural width ratio of the lateral and central incisors) should be applied in practice when treating a patient with canine substitution. Therefore, the involvement of patients in the clinical decisionmaking for the 
canine reshaping is essential for a successful canine substitution treatment $[26,42]$.

Another clinical application of the study findings is in the Digital Smile Design (DSD) technology during the Invisalign treatment $[43,44]$. A virtual simulation of the tooth movement and shape alteration for patients who need canine substitution would enhance patients' understanding of different treatment options as well as the communication between patients and clinicians.

Last but not the least, to clinically achieve the most attractive effects, the upper canine replacing the lateral incisor may also receive reshaping with resin, a veneer, or even a crown. Resin restoration can make the canine edge look more similar to the lateral incisor, which however may suffer from discoloration and risk of fall-off. A veneer can reshape not only the edge, but also the labial face of the canine, which is usually more convex compared to a lateral incisor. A crown, with more grinding of the dentin and usually necessitating root canal therapy, can change not only the shape, but also the size of the canine. However, many patients may not choose any of these three approaches, due to the adverse impacts on function (risks when biting hard food with the front teeth) and health (more grinding and even devitalization) of the tooth, and additional costs as well. Therefore, just grinding the canine cusp is an approach of great importance for such cases.

\section{Conclusions}

The most esthetic canine shape for canine substitution is a shape with the edge width of $62.5 \%$ of the central incisor crown width and the edge height of $0.5 \mathrm{~mm}$ gingival of the central incisor edge. The different collocations of the canine edge width and height affect dental esthetics of the canine during canine substitution treatment. The variation in esthetic preference among different groups of observers highlights the importance of individualized and patient-centered treatment.

\section{Acknowledgements}

The authors are grateful to Dr. Wen Liao and Dr. Shuai Wang for their valuable comments and help.

\section{Funding}

This study was supported by the National Undergraduate Training Programs for Innovation and Entrepreneurship of Sichuan University, and by the National Natural Science Foundation of China (grant No. 11372202).

\section{Availability of data and materials}

Data will not be shared due to the use of data in the future research.

\section{Authors' contributions}

RL made a substantial contribution to the literature review, preparation of the experimental images, data collection, analysis and interpretation, and drafting of the manuscript. LM made a substantial contribution to the concept of the study, drafting of the manuscript, and critical revision for the important intellectual content. PW made a substantial contribution to the design of the study and preparation of the experimental images. JH made a substantial contribution to the literature review, preparation of the questionnaire, and data collection. QM made a substantial contribution to the preparation of questionnaire and data collection and analysis. LZ made a substantial contribution to the data collection and analysis. WZ made a substantial contribution to the concept and design of the study, data analysis, and critical revision for the important intellectual content. YL made a substantial contribution to the concept and design of the study, data analysis, and critical revision for the important intellectual content. All the authors read and approved the final manuscript.

\section{Ethics approval and consent to participate}

The study protocol was approved by Ethics Committee of the State Key Laboratory of Oral Disease, West China School of Stomatology, Sichuan University, China.

\section{Consent for publication}

A written consent, signed by all the patients in this study, was recorded in order to use the anonymous data for scientific publication purpose.

\section{Competing interests}

The authors declare that they have no competing interests.

\section{Publisher's Note}

Springer Nature remains neutral with regard to jurisdictional claims in published maps and institutional affiliations.

\section{Author details}

'State Key Laboratory of Oral Diseases, National Clinical Research Center for Oral Diseases, Department of Orthodontics, West China Hospital of Stomatology, Sichuan University, Chengdu, China. ${ }^{2}$ Discipline of Orthodontics, Department of Oral Sciences, Sir John Walsh Research Institute, Faculty of Dentistry, University of Otago, Dunedin, New Zealand. ${ }^{3}$ State Key Laboratory of Oral Diseases, National Clinical Research Center for Oral Diseases, Department of Oral and Maxillofacial Surgery, West China Hospital of Stomatology, Sichuan University, No.14, South Renmin Road section 3, Chengdu 610041, China. ${ }^{4}$ Department of Orthodontics, Ninth People's Hospital, School of Stomatology, Shanghai key Laboratory of Stomatology, Shanghai Jiao Tong University, Shanghai, China.

Received: 17 August 2018 Accepted: 19 October 2018

Published online: 08 April 2019

\section{References}

1. Peck H, Peck S. A concept of facial esthetics. Angle Orthod. 1970;40(4):284-317.

2. Rakhshan V. Meta-analysis of observational studies on the most commonly missing permanent dentition (excluding the third molars) in non-syndromic dental patients or randomly-selected subjects, and the factors affecting the observed rates. J Clin Pediatr Dent. 2015;39(3):199-207.

3. Kleck RE, Strenta A. Perceptions of the impact of negatively valued physical characteristics on social interaction. J Pers Soc Psychol. 1980;39(5):861-73.

4. Behr M, Proff P, Leitzmann M, Pretzel M, Handel G, Schmalz G, et al. Survey of congenitally missing teeth in orthodontic patients in Eastern Bavaria. Eur J Orthod. 2011;33(1):32-6.

5. Van der Geld P, Oosterveld P, Van Heck G, Kuijpers-Jagtman AM. Smile attractiveness. Self-perception and influence on personality. Angle Orthod. 2007;77(5):759-65.

6. Silveira GS, de Almeida NV, Pereira DM, Mattos CT, Mucha JN. Prosthetic replacement vs space closure for maxillary lateral incisor agenesis: a systematic review. Am J Orthod Dentofac Orthop. 2016;150(2):228-37.

7. Schneider U, Moser L, Fornasetti M, Piattella M, Siciliani G. Esthetic evaluation of implants vs canine substitution in patients with congenitally missing maxillary lateral incisors: are there any new insights? Am J Orthod Dentofac Orthop. 2016;150(3):416-24.

8. Armbruster PC, Gardiner DM, Whitley JB Jr, Flerra J. The congenitally missing maxillary lateral incisor. Part 1: esthetic judgment of treatment options. World J Orthod. 2005;6(4):369-75.

9. Armbruster PC, Gardiner DM, Whitley JB Jr, Flerra J. The congenitally missing maxillary lateral incisor. Part 2: assessing dentists' preferences for treatment. World J Orthod. 2005;6(4):376-81.

10. Zachrisson BU, Rosa M, Toreskog S. Congenitally missing maxillary lateral incisors: canine substitution. Point. Am J Orthod Dentofac Orthop. 2011; 139(4):434 6, 8 passim. 
11. Rayner WJ, Barber SK, Spencer RJ. The effect of canine characteristics and symmetry on perceived smile attractiveness when canine teeth are substituted for lateral incisors. J Orthod. 2015;42(1):22-32.

12. Al-Jewair TS, Swiderski B. Orthodontic canine substitution for the management of missing maxillary lateral incisors may have superior periodontal and esthetic outcomes compared to an implant- or toothsupported prosthesis. J Evid Based Dent Pract. 2018;18(2):153-6.

13. Robertsson S, Mohlin B. The congenitally missing upper lateral incisor. A retrospective study of orthodontic space closure versus restorative treatment. Eur J Orthod. 2000;22(6):697-710.

14. Thordarson A, Zachrisson BU, Mjor IA. Remodeling of canines to the shape of lateral incisors by grinding: a long-term clinical and radiographic evaluation. Am J Orthod Dentofac Orthop. 1991;100(2):123-32.

15. Rosa M, Lucchi P, Ferrari S, Zachrisson BU, Caprioglio A. Congenitally missing maxillary lateral incisors: long-term periodontal and functional evaluation after orthodontic space closure with first premolar intrusion and canine extrusion. Orthod Fr. 2017;88(4):319-32.

16. Kiliaridis S, Sidira M, Kirmanidou Y, Michalakis K. Treatment options for congenitally missing lateral incisors. Eur J Oral Implantol. 2016;9(Suppl 1):S5-24

17. Johal A, Katsaros C, Kuijpers-Jagtman AM. State of the science on controversial topics: missing maxillary lateral incisors-a report of the Angle Society of Europe 2012 meeting. Prog Orthod. 2013;14:20.

18. Pini NP, et al. Digital analysis of anterior dental esthetic parameters in patients with bilateral maxillary lateral incisor agenesis. J Esthet Restor Dent. 2013;25(3):189-200.

19. Thierens LAM, Verhoeven B, Temmerman L, De Pauw GAM. An esthetic evaluation of unilateral canine substitution for a missing maxillary lateral incisor. J Esthet Restor Dent. 2017;29(6):442-9.

20. Brough E, Donaldson AN, Naini FB. Canine substitution for missing maxillary lateral incisors: the influence of canine morphology, size, and shade on perceptions of smile attractiveness. Am J Orthod Dentofac Orthop. 2010; 138(6):705.e1-9 discussion -7.

21. Wriedt $S$, Werner $P$, Wehrbein $H$. Tooth shape and color as criteria for or against orthodontic space closure in case of a missing lateral incisor. J Orofac Orthop. 2007;68(1):47-55.

22. Mota A, Pinho T. Esthetic perception of maxillary lateral incisor agenesis treatment by canine mesialization. Int Orthod. 2016;14(1):95-107.

23. Betrine Ribeiro J, Alecrim Figueiredo B, Wilson Machado A. Does the presence of unilateral maxillary incisor edge asymmetries influence the perception of smile esthetics? J Esthet Restor Dent. 2017;29(4):291-7.

24. Zachrisson BU. Improving the esthetic outcome of canine substitution for missing maxillary lateral incisors. World J Orthod. 2007:8(1):72-9.

25. Robertsson S, Mohlin B, Thilander B. Aesthetic evaluation in subjects treated due to congenitally missing maxillary laterals. A comparison of perception in patients, parents and dentists. Swed Dent J. 2010;34(4):177-86.

26. Haskell BS, Segal ES. Ethnic and ethical challenges in treatment planning: dealing with diversity in the 21st century. Angle Orthod. 2014:84(2):380-2.

27. Kuijpers-Jagtman AM, Nollet PJ, Semb G, Bronkhorst EM, Shaw WC, Katsaros C. Reference photographs for nasolabial appearance rating in unilateral cleft lip and palate. J Craniofac Surg. 2009;20(Suppl 2):1683-6.

28. Machado AW. 10 commandments of smile esthetics. Dental Press J Orthod. 2014;19(4):136-57.

29. Nikgoo A, Alavi K, Alavi K, Mirfazaelian A. Assessment of the golden ratio in pleasing smiles. World J Orthod. 2009;10(3):224-8.

30. Ward DH. A study of dentists' preferred maxillary anterior tooth width proportions: comparing the recurring esthetic dental proportion to other mathematical and naturally occurring proportions. J Esthet Restor Dent. 2007;19(6):324-37 discussion 38-9.

31. Bukhary SM, Gill DS, Tredwin CJ, Moles DR. The influence of varying maxillary lateral incisor dimensions on perceived smile aesthetics. Br Dent J. 2007:203(12):687-93.

32. De-Marchi LM, et al. Smile attractiveness of patients treated for congenitally missing maxillary lateral incisors as rated by dentists, laypersons, and the patients themselves. J Prosthet Dent. 2014;112(3):540-6.

33. Sarver DM. The importance of incisor positioning in the esthetic smile: the smile arc. Am J Orthod Dentofac Orthop. 2001;120(2):98-111.

34. Kokich VG. Esthetics: the orthodontic-periodontic restorative connection. Semin Orthod. 1996:2(1):21-30.

35. Ker AJ, Chan R, Fields HW, Beck M, Rosenstiel S. Esthetics and smile characteristics from the layperson's perspective: a computer-based survey study. J Am Dent Assoc. 2008;139(10):1318-27.
36. Rosa M, Zachrisson BU. Integrating space closure and esthetic dentistry in patients with missing maxillary lateral incisors. J Clin Orthod. 2007:41(9):56373 quiz 424

37. Al-Anezi SA. Orthodontic treatment for a patient with hypodontia involving the maxillary lateral incisors. Am J Orthod Dentofac Orthop. 2011;139(5):690-7.

38. Benkaddour A, Benyahia H, Mohtarim BE, Zaoui F. How to treat hypoplasia of the lateral upper incisors by canine substitution: a clinical case. Orthod Fr. 2017:88(2):199-208.

39. Krassnig M, Fickl S. Congenitally missing lateral incisors--a comparison between restorative, implant, and orthodontic approaches. Dent Clin N Am. 2011;55(2):283-99 viii.

40. Frush JP, Fisher RD. How dentogenic restorations interpret the sex factor. J Prosthet Dent. 1956;6(2):160-72

41. Rosa M, Olimpo A, Fastuca R, Caprioglio A. Perceptions of dental professionals and laypeople to altered dental esthetics in cases with congenitally missing maxillary lateral incisors. Prog Orthod. 2013;14(1):34

42. McLeod C, Fields HW, Hechter F, Wiltshire W, Rody W, Christensen J. Esthetics and smile characteristics evaluated by laypersons. Angle Orthod. 2011;81(2):198-205.

43. Walton DK, Fields HW, Johnston WM, Rosenstiel SF, Firestone AR, Christensen JC. Orthodontic appliance preferences of children and adolescents. Am J Orthod Dentofac Orthop. 2010;138(6):698.e1-12 discussion -9 .

44. Azaripour A, Weusmann J, Mahmoodi B, Peppas D, Gerhold-Ay A, Van Noorden CJ, et al. Braces versus Invisalign(R): gingival parameters and patients' satisfaction during treatment: a cross-sectional study. BMC Oral Health. 2015;15:69.

\section{Submit your manuscript to a SpringerOpen ${ }^{\circ}$ journal and benefit from:}

- Convenient online submission

- Rigorous peer review

- Open access: articles freely available online

High visibility within the field

- Retaining the copyright to your article

Submit your next manuscript at $>$ springeropen.com 